PERRONE, C. M.; DIAS, A. C. G.; SANTOS, A.S.; SOBROSA, G.M.R.; ENGELMAN, S. Geração Y...

\title{
Geração Y e sociedade de controle: desdobramentos acerca do trabalho
}

\author{
Generation Y and control society: developments about work
}

http://dx.doi.org/10.5007/2178-4582.2014v48n1p154

\author{
Cláudia Maria Perrone, Ana Cristina Garcia Dias, Anelise Schaurich dos Santos \\ Universidade Federal de Santa Maria, Santa Maria/RS, Brasil \\ Gênesis Marimar Rodrigues Sobrosa \\ Universidade do Vale do Rio dos Sinos, São Leopoldo/RS, Brasil \\ Selda Engelman \\ Centro Universitário Metodista, Porto Alegre/RS, Brasil
}

\begin{abstract}
Este artigo investiga as consequências da nova configuração do controle para os processos organizacionais a partir da sua recomposição proposta com a chegada da Geração Y nas empresas. Para tanto, foi realizada a análise de conteúdo de entrevistas feitas com dez jovens. Percebeu-se que há uma grande diferença entre a internalização do controle e a internalização da flexibilidade. A necessidade de estabilidade é entendida como um problema privado, em resposta à flexibilidade da empresa. O trabalho é visto não somente como obrigação moral ou econômica, mas como parte da vida, o que implica reconhecimento afetivo e satisfação. Tal perspectiva é o ponto de partida para o desenvolvimento de estratégias de resistência e enfrentamento contra os mecanismos de controle e a colonização dos afetos impostos pelo mundo organizacional.
\end{abstract}

Palavras-chave: Geração Y - Sociedade de Controle - Controle Organizacional.
This paper investigates the consequences of the new configuration of control over the organizational processes from its proposal of restoration with the arrival of Generation $Y$ in the companies. For such purpose, we conducted a content analysis of ten interviews carried out with young people. It was noticed that there is a big difference between the internalization of control and the internalization of flexibility. The need for stability is seen as a private matter, in response to the company's flexibility. Whilst work is seen not only as a moral and economic obligation but also as part of life, which implies recognition and emotional satisfaction. This perspective is the starting point for the development of strategies of resistance and confrontation against the mechanisms of control and colonization of affects imposed by the organizational world.

Keywords: Generation Y - Control Society - Organizational Control.

As mudanças tecnológicas e sua relação com o monitoramento e controle social são cada vez mais recorrentes nas sociedades contemporâneas e conectam-se com importantes transformações sociais. $\mathrm{O}$ foco sobre a presença de tecnologias no espaço societário torna possível uma diversidade de posições analíticas. A tecnologia abriga e concretiza um modo de pensamento e constitui um ângulo privilegiado para fazer emergir as visibilidades e invisibilidades de uma época. Também pode funcionar como ponto de partida para uma investigação acerca do funcionamento do poder na atualidade. As novas tecnologias têm como um de seus efeitos a sensação de contínua visibilidade, 
fato que levou Deleuze (1990) a definir nossa sociedade como a "sociedade de controle". Ele propõe a ideia de que as instituições não constituem mais o ponto nevrálgico da normalização, pois o controle tornou-se difuso no seu acoplamento com os sistemas de informação digital, caracterizados pela velocidade, ubiquidade e precisão elevada.

A hipótese deste trabalho é a de que a abordagem teórico-conceitual do conceito de controle de Gilles Deleuze, mediatizado pelas transformações tecnológicas, com a ênfase em uma das suas formas específicas - o controle difuso e pós-panóptico - denuncia as transformações nas organizações e na gestão de pessoas associadas às tensões da entrada no mercado de trabalho da geração Y. Para tanto, será discutido, resumidamente o conceito de controle no âmbito das teorias das organizações. A partir das análises de Michel Foucault e Gilles Deleuze buscou-se evidenciar a nova configuração do controle e suas consequências para os processos organizacionais, por meio da sua recomposição proposta pela chegada da Geração Y nas empresas.

\section{O mundo pós-fordista e as organizações}

No âmbito da análise das mudanças e transformações organizacionais das últimas décadas há certo consenso em relação à passagem da produção em massa à produção flexível; ao aumento do número de pequenas e médias empresas ao uso de novos métodos de gerenciamento; ao surgimento do Toyotismo (em substituição ao Fordismo) ao modelo de licenciamento e subcontratação e às burocracias verticais, dando lugar à empresa horizontal (CASTELLS, 1999). Autores como Lévy (1993; 1999), Schaff (1995), Castells (1999), Lima (2000), Turban et al. (2004) enfatizaram a centralidade da mudança ocorrida no desenvolvimento tecnológico contemporâneo com a chegada das tecnologias da informação, processamento e comunicação e o uso combinado do computador com outros meios de telecomunicação. Essas tecnologias apresentam alto poder de transformação social, com capacidade de modificar as formas de organização do trabalho. Boltanski e Chapello (2009) consideram que as novas formas e relações de produção no capitalismo estabeleceram uma estrutura de rede, na qual as empresas capitalistas e os trabalhadores tendem a buscar o máximo de mobilidade de informações, de conexões úteis, articuladas e prontas para se adequarem às constantes transformações do mercado global.

A confluência das mudanças tecnológicas, sociológicas, psicológicas e gerenciais pode ser configurada na análise da Geração Y. Essa geração engloba jovens com idades entre 18 e 30 anos, nascidos entre 1984 e 2002, que apresentam como traço definidor a sua relação com a tecnologia. Elmore (2010) destaca que é tangível o impacto do " $i$ " mundo sobre esses jovens; o crescimento deles ocorreu literalmente online, uma vez que vivenciaram ativamente o uso da internet, iPod, iPhone, iMovie, iTunes. Essas tecnologias têm um profundo impacto sobre o modo como eles pensam, imersos em imagens, 
em um universo permanentemente relacional, comunicacional, de inteligência associada e coletiva. Isso engendra permanentemente comportamentos singulares nessa primeira geração efetivamente global.

Em uma conferência apresentada em 1978, Foucault já antecipava as mudanças nos países industrializados ligados às novas configurações do capitalismo:

\begin{abstract}
Nesses últimos anos, a sociedade mudou e os indivíduos também; eles são cada vez mais diversos, diferentes e independentes. Há cada vez mais categorias de pessoas que não estão submetidas à disciplina, de tal forma que somos obrigados a pensar o desenvolvimento de uma sociedade sem disciplina (FOUCAULT, 2003, p. 307).
\end{abstract}

Em suas análises sobre a sociedade disciplinar, Foucault já apontava com clareza a dupla articulação entre as exigências de um modo de produção capitalista industrial em desenvolvimento e as novas formas de subjetivação necessárias para compor com essa ordem econômica e social. Tal articulação prefigurava o conceito da sociedade de controle proposto no ensaio de Deleuze (1990). As tensões que a geração Y tem provocado nas organizações estão relacionadas com este momento de mudança.

\title{
A sociedade de controle de Gilles Deleuze
}

Uma hipótese central para Deleuze é a de que a nova modulação do tecido social está diretamente relacionada com a nova forma do capital e sua mudança tecnológica. O pressuposto material do novo capitalismo é uma complexa matriz informacional caracterizada por redes informáticas e telemáticas de comunicação denominadas TICS (Tecnologias de Informação e Comunicação). Por meio dessa matriz tecnológica contituiu-se a "sociedade global", um complexo social de redes virtuais, interativas e controlativas que integram a produção e reprodução do mercado global. Podemos acompanhar a complexidade dessa mudança do poder e do controle retomando os dispositivos disciplinares. Foucault problematizou essa relação através da tecnologia do panóptico. $\mathrm{O}$ poder, devido à sua situação privilegiada, se manteria fora do alcance dos indivíduos, enquanto estes estariam em uma situação de constante observação. Isso garantiria uma posição de transparência para o poder diante dos olhos dos indivíduos (FOUCAULT, 1998; RHEINGOLD, 2002).

A sociedade de controle é reticular, interconectada tecnologicamente. $\mathrm{O}$ poder perde o seu caráter hierárquico e torna-se disperso em uma rede planetária. Isso poderia significar que a dicotomia opacidade-transparência não operaria mais. Contudo, a complexidade é maior, como aponta Deleuze (1990). O poder seria ilocalizável, pois se encontra disseminado entre os nós da rede. Sua ação não é mais vertical, mas sim horizontal e impessoal, uma vez que a 
verticalidade esteve sempre associada à imagem de alguém (ícone que preenche o lugar do poder). A sociedade de controle é axiomatizada e as instâncias de poder estão dissolvidas entre os indivíduos. Assim, o poder não tem mais uma face e uma identidade.

O importante é a modulação constante dos fluxos sociais, seja através do fluxo financeiro, do consumo ou da expansão ilimitada das redes de comunicação. O poder é tão sofisticado quanto a regulação dos elementos imateriais da sociedade: informação, conhecimento, comunicação. Nesse contexto, o Estado também sofre uma alteração. A reprodução da vida social é realizada de um modo diverso ao disciplinar, pois foi em grande medida privatizada em dois sentidos diversos. Há a queda da responsabilidade pelos espaços de poder societal concentrado e o abandono das questões de integração social ao jogo livre da iniciativa privada. Esse processo é, em grande parte, desinstitucionalizado, ou seja, o sujeito é entregue à sua autoformação. A incerteza confronta o indivíduo diretamente. Diante de enorme pressão, o sujeito isolado tem como arma apenas sua ação individual.

A incerteza e a indeterminação produzidas a partir da erosão do controle externo são resolvidas através dos esforços de autoformação e autoafirmação. A inadequação é a nova face do desvio, a maior penalidade para a falha individual. Não se trata mais da distância em relação a um padrão claro e sólido ao qual o sujeito deveria se ajustar, mas da leitura individual de que o sujeito falha em adquirir. A flexibilidade e a necessidade de se manter em movimento são novos parâmetros a serem alcançados.

O surgimento da sociedade de controle está relacionada com o surgimento do capitalismo pós-industrial, caracterizado pela predominância da economia do conhecimento. Nesse tipo de economia predominam o trabalho imaterial (ou seja, a produção de bens imateriais, como conhecimento, tecnologias e serviços), a comunicação e a informação. A ênfase mudou da fábrica, como local de produção, para a emergência de formas imateriais ou baseadas em informações de produção e distribuição. Novas maneiras de lidar com dinheiro, lucros e seres humanos decorreram dessas mudanças. Mais do que com lugares disciplinares como a fábrica, a prisão e suas formas análogas (quartéis, hospitais, família), a sociedade de controle deu lugar à corporação, a "um espírito" que, sem forma específica, volume ou localização permanente, permeia toda a paisagem social.

Essa mudança afetou o processo de trabalho, incluindo novas formas de gestão dos funcionários ao promoverem um grau de colaboração diverso daquele exigido nas linhas de produção de uma fábrica. Deleuze (1990) descreve a incitação da rivalidade como uma forma saúdavel de emulação, a motivação que contrapõe os indivíduos uns contra os outros. Prática agravada, em parte, por meio da mediação contínua e da comparação de desempenho generalizada no trabalho e em outras esferas da vida do sujeito. As massas trabalhadoras, que entravam e saíam de uma fábrica, são transformadas em "combatentes 
solitários" nessa sociedade de controle (BUSK, 2001, p. 104).

As novas tecnologias informacionais solicitam uma inteligência reflexiva (LOJKINE, 1995). As demandas sociotécnicas se organizaram ao redor do "modelo das competências profissionais", com saberes em ação, talentos, capacidade de inovar, criatividade e autonomia no local de trabalho. $\mathrm{O}$ modelo das competências dissemina o novo trabalhador do controle que apresenta noções estruturantes de flexibilidade, transferibilidade, polivalência e empregabilidade, que irão determinar o uso, controle, formação e avaliação de desempenho no trabalho.

Na gestão por competências, os objetos complexos da revolução das redes informacionais são meios técnicos "inteligentes" ou "tecnologias da inteligência" que criam "espaços virtuais" de caráter social, ou podem ser "interativos" ou "controlativos", cuja matéria-prima é a informação (ALVES, 2011). Esse novo espaço foi chamado por Bhimani (2003) de economia digital, na qual colaborações estão intrinsecamente associadas aos sistemas de comunicação digital, reconfigurando e personalizando os mesmos.

$\mathrm{Na}$ sociedade disciplinar, o poder foi exercido por meio de uma rede de instituições heterogêneas, cada uma delas possuindo seu próprio sistema de controle fechado em si mesmo, com uma população-alvo e uma produção de efeito disciplinar homogêneo. No mundo do controle, o efeito pós-panóptico é o de que os sistemas contemporâneos de controle são implantados a partir de vários ângulos, sobrepostos uns aos outros, formando redes interligadas de disseminação da informação em toda a paisagem social. O exercício do poder já não está confinado a um ambiente institucional, mas é exercido através da difusão das lógicas do controle, a partir das diversas redes de informação.

Para problematizar a distinção entre a sociedade disciplinar e a sociedade de controle, Deleuze (1990) assinalou que na sociedade disciplinar há sempre um começar de novo (da escola à caserna, da caserna para a fábrica), enquanto na sociedade de controle nada está acabado, todos os estados são metaestáveis e coexistentes em uma modulação - sistema universal e infindável de formação. $O$ controle da informação é um inventário entre as instituições, realizado a partir de múltiplos sistemas de informações (e olhares), com diferentes capacidades e procedências. Nesse arranjo, o trabalhador está permanentemente ligado e sujeito a vários controles, inseparáveis nas suas variações.

Bhimani (2003), concordando com as ideias de Deleuze (1990), explica que, por um lado, as tecnologias da informação, como a internet, tem liquidado com as fronteiras físicas entre o trabalho e a esfera pessoal, não existindo mais uma segmentação entre um espaço e outro. A transferência de atividades relacionadas ao trabalho à esfera doméstica e ao privado, no entanto, não afeta o controle. Com os sistemas de informação, a exemplo da internet, os resultados são ainda mais precisos com os seus diversos cruzamentos de fluxos.

Há maior alcance das informações potencialmente relevantes para medir e avaliar o desempenho. Há um aumento de informações em circulação, não 
necessariamente ligadas a empresa, que podem ser usadas para dar conta do desempenho e do perfil do funcionário. Há dúvidas quanto a confiabilidade dessas informações, mas todas as instituições estão abertas, em redes simultâneas. Há sobreposição de visibilidades e, portanto, coexistência em uma mesma modulação de controle. Estar sujeito a uma linha de visibilidade não está mais restrito a uma instituição fechada, mas, sim, a ligações que podem ser estabelecidas a partir de um clique ou da introdução de uma senha. $\mathrm{Na}$ sociedade de controle, estudar os sistemas de controle de uma empresa inclui um olhar sensível às múltiplas linhas de fluxo de visibilidade, pois as tecnologias de informação perfuram os recintos protegidos com a sua visibilidade (BHIMANI, 2003).

As tecnologias de informação e comunicação viabilizaram a gestão de relações de uma empresa em rede com outras empresas, na qual é possível estabelecer controle sobre partes da operação da outra empresa, sem absorvê-la. Uma empresa atinge seu objetivo não somente pela sua organização interna, mas principalmente pela forma de relação que estabelece com outras empresas. Os novos arranjos de gestão incluem a multiplicação de participações minoritárias de companhias coligadas, os acordos de tercerização e a cooperação interempresas, que levam à criação da empresa-rede, tornando permeáveis as fronteiras entre as companhias. A difusão e a velocidade da informação dão o formato invasivo ao controle, pois a vida passa a ser gerida por meio de controle contínuo e da comunicação instantânea entre os diversos nós da empresa-rede.

O "homem-como-corpo" (FOUCAULT, 2003), orientado por técnicas disciplinares, uma vez que penetra no ambiente pós-panóptico, passa a ser coptado por códigos digitais, assim tornam-se "divíduos" (DELEUZE, 1990) identificados por cifras ou senhas ou perfis digitais (JOHSON; WAYLAND, 2010). Esses traços digitais, disseminados em um ambiente aberto, tornam possível monitorar o comportamento e as ações (e-mails enviados, horas trabalhadas, compras) e são usados para regular e prever o comportamento. Da mesma forma, são utilizados para exercer a vigilância chamada de "triagem social", na qual, conscientemente, ou não, as informações dos indivíduos são coletadas e analisadas com o objetivo de classificá-los em categorias que dão acesso, ou não, a certas oportunidades (JOHSON; WAYLAND, 2010, p. 23). $\mathrm{Na}$ sociedade de controle, a linguagem numérica do controle é feita por códigos que marcam o acesso à informação. A exigência contínua para confirmar sua identidade e posição em relação ao próprio indivíduo é evidente na quantidade de vezes que uma senha ou número de identificação pessoal é introduzido para login na rede de um banco, como uma caixa automática de pagamento, e-mails, intranet da empresa ou com a introdução de identificações biométricas. Essas exigências continuamente acoplam e armazenam, ao longo de redes de informação, avaliações do desempenho, que facilitam a automatização do controle e da regulação do movimento ao conceder ou negar acesso a certos aspectos da sociedade (bônus, arquivos ou acesso a redes). 
A nova rede panóptica é a própria rede de tecnologias da informação com dados estatísticos e algoritmos que ajudam a mediar o comportamento do trabalhador monitorado. Desenvolvem-se continuamente contas de desempenho conectadas com inúmeras linhas de visibilidade que seguem os movimentos dos empregados. A circulação de informações entre espaços que eram confinados nos seus sistemas de controle, a importância da velocidade e da ubiquidade dos dispositivos de monitorização são as características do novo ambiente geral de controle, no qual a gestão dos sistemas de controle estão situados. Há outra mudança importante: somente as atitudes que se destacam do fluxo chamam a atenção. É sobre perfis que opera a visibilidade, que não está mais individualizada, mas sinaliza um erro, um desvio de fluxo que opera indicando a variação e a incerteza.

O indivíduo mesmo é o componente essencial na geração de dados e inventários sobre os perfis. Por exemplo, os telefones inteligentes fornecidos pelas empresas são utilizados para manter o controle da localização, o número de telefonemas, os e-mails. Os sistemas automatizados de Balanced Scorecard são usados para gerar uma representação digital do desempenho, e este dado pode gerar permutações com outras avaliações da empresa - benchmarks de desempenho histórico e em tempo real. Cada uma dessas representações parciais (BALL et al., 2010) são facilmente implementadas e armazenadas em bases de dados com intermináveis coletores e gestores de informações, tais como governo, agências de marketing, empregadores, tornando-se simultaneamente peças de estratégias de marketing, desempenho e/ou relatórios financeiros. O ponto é que o indivíduo torna-se um agregado de vestígios digitais, facilmente rastreáveis pela convergência de dados e controles, com a companhamento instantâneo e contínuo na geração de perfis digitais.

\section{A Geração $Y$ e as organizações}

Não existe consenso na literatura sobre quando a geração $Y$ começa e termina. Contudo, percebe-se um alinhamento das características dessa geração e o contexto em que ela se desenvolveu. Parte-se do pressuposto que a experiência e o compartilhamento dos mesmos momentos históricos teriam influenciado a forma de pensar e agir das pessoas que viveram na mesma época, o que concede características próprias a toda uma geração. As vivências comuns à geração Y são o desenvolvimento tecnológico, a globalização e a competitividade, que exigiram profissionais cada vez mais capacitados para atuarem nas organizações a partir dos anos 1980. Assim, se para muitos dos trabalhadores das outras gerações foi difícil se adaptar a esse novo contexto, para os jovens da Geração $\mathrm{Y}$, que já nasceram nessa realidade, a aderência às características do mundo do trabalho atual é natural (SANTOS, 2011).

De maneira geral, os jovens da Geração Y vivenciaram o mundo pós Guerra Fria. Esse foi o momento em que os Estados Unidos da América se consolidaram como a maior potência econômica e militar do mundo. No Bra- 
sil, os jovens da Geração Y vivenciaram o impeachment do presidente Fernando Collor em 1992 e a criação do Plano Real, o qual retomou a estabilidade financeira do país após inúmeras tentativas. Nessa época, o fenômeno da globalização ficou mais evidente, o que incentivou a expansão de clientes, fornecedores e parceiros para as empresas. O Brasil também ganhou destaque como um dos quatro países em desenvolvimento mais promissores ao lado da Rússia, Índia e China. Além disso, a Geração Y cresceu em contato com o rápido desenvolvimento tecnológico. Isso possibilitou a obtenção de um nível de conhecimento superior às gerações anteriores na maioria dos casos. Já no âmbito familiar, grande parte da Geração Y teve de se acostumar com o divórcio dos pais e, consequentemente, a viver em duas casas diferentes com famílias distintas (SANTOS, 2011).

Além disso, o maior diferencial entre a Geração Y e as anteriores está na experiência quase fusional com a tecnologia e a capacidade de interação com a ela que essa geração apresenta. Don Tapscott (1999) foi um dos primeiros autores a organizar as características da Geração Y em seu livro Grown Up Digital: How the Net Generation is Changing your World, a partir de uma pesquisa realizada com jovens em doze países. O autor identificou as seguintes mudanças nas perspectivas dos jovens, representantes dessa geração:

1) Como trabalhadores e gestores, eles têm uma postura colaborativa, colocando em colapso a hierarquia rígida e forçando as organizações a repensar como recrutam, compensam, desenvolvem e supervisionam os seus talentos. A própria ideia de gestão e liderança é posta em crise, pois eles realizam um êxodo das corporações para start-ups recém iniciando.

2) Como consumidores, eles podem ser definidos como proconsumidores (prosumers), querem participar como colaboradores na inovação dos produtos e serviços. O conceito de marca altera-se e pode ser entendido como um processo permanente de mudança por causa deles.

3) Na educação, eles estão forçando uma mudança no modelo pedagógico, de um modelo professor-centrado para um modelo de colaboração aluno-centrado.

4) Em relação à família, há uma um elemento de mediação que alterou irreversivelmente as relações entre pais e filhos, a Internet.

5) Como cidadãos, eles questionam como os serviços governamentais são concebidos e entregues e quais são os imperativos da cidadania e como a democracia deve ser. Eles apostam na mudança social via o engajamento político.

6) Na sociedade como um todo, há a aposta no poder da Internet como uma 
riqueza global, como um poder político novo e um ativismo social mais poderoso.

Outra caracterização da Geração Y foi realizada por Allen (2005), que a definiu como uma geração digitalmente conectada e globalizada, tecnicamente competente, educada e aberta à diversidade. Essa geração deseja desafios intelectuais, precisa ter sucesso, busca aqueles que podem auxiliar no seu desenvolvimento, se esforça para fazer diferença e medir seu próprio sucesso. A união do trabalho com as metas pessoais é importante para esses indivíduos, que acreditam que a realização de um trabalho significativo torna o mundo melhor; assim, são indivíduos comprometidos com valores comuns. O domínio da tecnologia é uma competência que eles levam ao seu local de trabalho. São jovens que conviveram com fortes estressores que vão desde a pressão para se destacar na escola, o divórcio dos pais e a necessidade de estabelecer novos relacionamentos em diferentes contextos. Esses indivíduos estão acostumados a serem ativos nas decisões familiares e esperam contribuir nas decisões das organizações na qual estão empregados (JONHS, 2004). Assim, percebe-se que familiaridade com tecnologia, rápida adaptação às mudanças, necessidade de respostas e resultados imediatos, preferência por valores individuais em relação aos sociais, autonomia na execução de tarefas, gosto pelo desafio e equilíbrio entre vida pessoal e profissional são características convergentes dessa geração (SANTOS, 2011).

Quando as características da Geração Y são observadas, nota-se compatibilidade com as exigências do cenário organizacional atual (SANTOS, 2011). No local de trabalho, a Geração Y tende a favorecer um estilo de gestão horizontal e sem controles rígidos, que valoriza a velocidade, customização e interatividade. Assim, esses indivíduos não gostam de lentidão e desejam um feedback imediato sobre o seu desempenho (FRANCIS-SMITH, 2004). É uma geração verdadeiramente global, socialmente consciente, que apresenta o melhor desempenho quando suas habilidades são identificadas e combinadas com um trabalho desafiador (MARTIN; TULGAN, 2001). Os indivíduos dessa geração procuram balancear a vida pessoal e profissional, aspirando por vínculos mais fortes no ambiente de trabalho (MARTIN; TULGAN, 2001; SANTOS, 2011).

As expectativas em relação ao trabalho desses indivíduos foram descritas por Dytchwald, Erickson e Morison (2006). Os autores identificaram: responsabilidade individual e liberdade para tomar decisões, ambiente de trabalho agradável, que fomente relações sociais, oportunidades de aprendizagem e crescimento, colaboração e tomada de decisões em conjunto, feedback contínuo, comunicação aberta e gestores próximos e acessíveis, respeito ao seu estilo de vida e trabalho, retribuição por resultados e flexibilidade temporal e espacial.

As diversas caracterizações da Geração Y sobrepõem-se em diversos pontos, mas elas têm em comum a ênfase na autonomia, no desprendimento das 
tradições, no individualismo e em um posicionamento ativo diante de repertórios socioculturais herdados. Essa geração possui um contrato de trabalho diverso da geração anterior, cujo perfil de lealdade à organização traz fortes traços e vícios da revolução industrial. Os jovens não são fiéis às empresas, eles valorizam a vida das pessoas e são altamente colaborativos.

A nova geração desafia o próprio modelo de negócios e a sua capacidade de inovação e trabalho é inquestionável como novo valor intangível das empresas. No entanto, é inegável que os jovens rompem com categorias sociológicas de diversas tradições, que as problematizações de Deleuze (1990) podem nos auxiliar a pensar como experiência, fluxo e desafios da sociedade de controle.

Devido às características dessa geração, tornou-se um desafio para as empresas lidar com a ela, pois escapa aos fatores ambientais restritivos. A imagem desses jovens para as organizações é a de que eles têm algo de não domesticável e de altamente inventivo e inovador. Paradoxalmente, são trabalhadores relacionais, imersos em fluxos e redes de todas as ordens, com uma inteligência associada ao coletivo, o que engendra constantemente novas formas de subjetividade. A resistência e a criação desses jovens caminham juntas. Esse é paradoxo que demanda uma nova ação das empresas. A recusa de uma relação de trabalho, que pode ser mais bem definida como uma recusa da alienação da vida, é parte fundamental para o investimento pessoal na inovação e desenvolvimento nessa nova geração.

\section{Método}

A pesquisa em subjetividade humana requer estratégias de investigação que dêem conta da sua complexidade. Assim, este estudo apresenta um delineamento qualitativo que tem como objetivo investigar o universo de significados, relações, motivos, crenças, valores e atitudes do ser humano (MINAYO, 2000).

Participaram dessa pesquisa dez jovens, seis homens e quatro mulheres, com idades variando entre 21 e 29 anos. Todos os sujeitos já trabalhavam há, no mínimo, dois anos, possuem curso superior e três já estão cursando pós-graduação. Dois jovens são concursados em empresas públicas. A metade da amostra pertence à classe $\mathrm{B}$ e a outra metade à classe $\mathrm{C}$. Os participantes foram contatados a partir da rede de contatos dos pesquisadores deste estudo. Foram determinados como critérios para sua inclusão no estudo: pertencer à geração Y, ou seja, ter nascido entre 1991 e 1998, e estar colocado no mercado de trabalho, exercendo alguma atividade há pelo menos dois anos.

Para a coleta dos dados foi construído um roteiro de entrevista semiestruturada. Nesse tipo de entrevista, os questionamentos são flexíveis e questões adicionais podem ser acrescentadas, de acordo com o relato de cada entrevistado. Os participantes foram convidados a participar da pesquisa, sendo nessa 
ocasião explicados os objetivos e procedimentos do estudo. Todos assinaram o Termo de Consentimento Livre e Esclarecido antes do início das entrevistas. As entrevistas foram realizadas na sala de supervisão do Departamento de Psicologia da Universidade Federal de Santa Maria (UFSM). Todos os preceitos éticos previstos na Resolução do Conselho Nacional de Saúde (BRASIL, 2012) que regulamenta a realização de pesquisa com seres humanos foram observados na condução do estudo.

Foi utilizada a análise de conteúdo temática categorial para avaliar as questões abertas. A análise de conteúdo é um conjunto de técnicas de análise das comunicações que utiliza procedimentos sistemáticos e objetivos, que permitem inferir conhecimentos a partir dos conteúdos das mensagens analisadas (BARDIN, 2010). Este tipo de análise busca a produção de inferências a respeito do conteúdo da comunicação, trabalhando com a palavra, a partir da categorização de unidades de texto.

\section{Resultados}

A partir da análise de conteúdo (BARDIN, 2010), foram identificadas as categorias que serão descritas a seguir.

Relação com o emprego atual

A quase a totalidade dos jovens expressou insatisfação com o seu emprego atual. A motivação para permanecerem nas organizações de trabalho está relacionada com o salário, certa flexibilização de tempo, regime de trabalho e arranjo de horários. Isso torna possível continuar a formação profissional ou, pelo menos, o planejamento para continuar os estudos.

Não trabalho com o que gosto, mas o emprego atende minhas demandas financeiras (Entrevistado 1).

Como eu tinha como objetivo pessoal seguir estudando, optei pelo emprego que estou atualmente. Ele me possibilita tempo sem ter perdas financeiras significativas; entretanto, preferia as atividades exercidas em outras empresas (Entrevistado 2).

Apenas dois entrevistados relataram satisfação com o emprego atual. A satisfação é decorrente do caráter desafiador no exercício da atividade, que permite o desenvolvimento e amadurecimento profissional.

\section{A melhor organização para trabalhar}

Os entrevistados manifestaram nas entrevistas que aspiram trabalhar em empresas que contribuam para o seu desenvolvimento profissional e pessoal. 
Segundo eles, isso ocorre por meio do enfrentamento cotidiano de desafios e pela garantia de autonomia para expor ideias e criar.

Uma empresa que dê autonomia para expor minhas ideias e inovar. Que tenha um clima agradável, onde as pessoas cooperem umas com as outras e pensem no todo. Um lugar que eu tenha liberdade de expressão e flexibilidade nos horários (Entrevistado 3$)$.

Também foi enfatizada a necessidade de a organização permitir a flexibilização de horários aos funcionários; que proporcione, principalmente, a continuidade de sua formação acadêmica. Foi ressaltada, ainda, a importância de um clima organizacional agradável, democrático, de abertura para a comunicação, a cooperação e a importância de incentivos de crescimento, por meio de um plano de carreira.

É preciso que a empresa valorize o funcionário, invista na sua qualificação, que tenha plano de carreira e pense em estimular seu crescimento e aperfeiçoamento (Entrevistado 6).

Em menor proporção, foi ressaltada a importância da organização manter uma coerência entre os discursos e as práticas organizacionais e a compatibilidade entre os valores da organização e os valores pessoais dos funcionários.

\section{A pior organização para trabalhar}

Os entrevistados manifestaram opiniões negativas em relação às organizações com culturas rígidas e hierarquizadas, com pouca flexibilidade de horário e com pressão excessiva por resultados. Seguidamente, essas organizações não prestam o devido valor ao que foi conquistado pelos funcionários e não atentam para as opiniões de seus colaboradores. Ainda, foram relacionadas as empresas que não possuem planos de carreira e que não investem em seus funcionários.

Uma empresa difícil para trabalhar seria aquela no qual as minhas opiniões não fossem levadas em consideração, onde não houvesse valorização pelo resultado que entrego, com uma cultura rígida e autocrática, sem nenhuma flexibilidade de horário (Entrevistado 3).

Uma empresa muito rígida, com metas excessivas e que não valoriza o funcionário eu não conseguiria trabalhar (Entrevistado 7). 


\section{O momento de sair de uma organização}

Para os entrevistados, a intenção de trocar de emprego é motivada essencialmente pelas metas excessivas, o salário não compatível com a função e a não flexibilização de horários de trabalho, que inviabiliza outros projetos pessoais e profissionais. Surgiram outros fatores como um clima de trabalho tenso e marcado por conflitos, falta de desafios profissionais, conflito entre valores pessoais e organizacionais e conflitos éticos.

Há um momento em que não se aguenta mais a pressão. É uma preocupação excessiva com metas e a gente começa a duvidar da capacidade de trabalhar. O clima pesado também, com pressão excessiva da chefia, fica muito ruim. E se o salário não for bom, fica pior ainda. É hora de sair (Entrevistado 7).

É um momento em que teu trabalho não é valorizado, o teu salário não é compatível com teus resultados e a empresa não está mais agregando na minha vida e na minha carreira; quando não é permitido flexibilização de horários ou se eu fosse induzido em faltar com a ética profissional (Entrevistado 3).

\section{Relação entre o trabalho e a vida pessoal}

A quase totalidade definiu a relação entre o trabalho e a vida pessoal como uma relação que deveria ser equilibrada, mas a separação entre as duas esferas é quase impossível. O equilíbrio é considerado uma situação idealizada. A meta é que não ocorra uma influência negativa entre uma e outra esfera da vida.

Imagino que deveria ser equilibrada, mas não é. Separar é quase impossível (Entrevistado 7).

É uma linha muita tênue separando as duas vidas, elas se encontram e se cruzam muitas vezes, só que uma não deve influenciar negativamente a outra (Entrevistado 10).

\section{Critérios para a seleção de uma empresa para trabalhar}

Os entrevistados definiram como critérios para a busca de uma empresa para trabalhar a indicação de amigos, os salários oferecidos, as possibilidades de crescimento profissional e a flexibilidade de horários. 
É importante o que dizem os meus amigos. Aí começo a me informar sobre a empresa, leio, visito o site, tento descobrir os salários como são (Entrevistado 9).

O salário é importante e é importante entender o funcionamento da empresa. Tento localizar algum amigo que possa me dizer alguma coisa sobre a empresa ou realizar a minha indicação (Entrevistado 5).

\section{Recolocação profissional}

Os jovens identificaram como essencial para a recolocação profissional a sua rede de contatos e sua constante formação e atualização profissional. Alguns entrevistados apontaram a importância da imagem profissional positiva no mercado de trabalho e as referências fornecidas pelas empresas em que já trabalharam.

Acredito que o principal são as referências no mercado, isto é, acredito que em qualquer profissão você fica conhecido no meio, positiva ou negativamente, a boa imagem ajuda. Mas isso aliado à rede de contatos. E cursos, especializações, treinamentos (Entrevistado 3).

Auxilia muito estar atualizado, fazer cursos, muito conhecimento na área pretendida, a rede de contatos, estar atualizado em tudo (Entrevistado 9).

\section{Controles Organizacionais}

Os entrevistados ressaltaram em diversos momentos de suas entrevistas a questão das metas e da pressão que sentem em relação ao seu desempenho. Contudo, muitos consideram que realizar treinamentos em casa não é um problema.

Pressionam o trabalhador a cumprir metas absurdas, o trabalhador leva parte do trabalho para sua casa. Outro aspecto que eu não gosto é de ter um intervalo muito pequeno entre um turno e outro. Claro, eu até tenho, mas fico trabalhando. E tem também a vigilância dos chefes ou câmeras no horário de trabalho. Até no celular, sei que controlam. Não tenho certeza se no Face, talvez... Acho que sim... (Entrevistado 1) 
É melhor fazer alguns [treinamentos] em casa que no trabalho. Estou fazendo alguma coisa, atendendo e tem que cuidar da janelinha do treinamento ao mesmo tempo (Entrevistado 4).

Meu chefe é muito esforçado, ligado. Ele manda e-mails de madrugada e durmo às vezes com o celular perto, para que eu possa responder logo. Final de semana, também. Se recebo qualquer chamada de trabalho, respondo logo. É importante resolver, ser proativo, senão fica até segunda. Sei lá, pega bem. (Entrevistado 5).

Tem uma hora que é tanta coisa, nem sei porque... Começa a ter preocupações excessivas em relação ao seu trabalho. Se ele é ou não bem visto na empresa, começa a duvidar de sua capacidade de exercer a função. É meio assim, por nada... Também quando começa a pensar o tempo todo sobre o seu trabalho, fica preocupado sempre até nos dias de folga. Claro tem a pressão excessiva da chefia e dos colegas e também o clima pesado que é instalado quando a equipe não vai bem. Mas é que às vezes tá tudo bem, não tá mal. Muitas vezes, a equipe se perde no foco e deixa de lado o trabalho proposto e começa um ciclo vicioso de um vigiar o outro e isso é muito ruim. Todos vigiam todos, em todos os lugares, se sai de noite, como é que é... O cara tá nisso o tempo todo. Agora, até terminei o meu namoro (Entrevistado 7).

\section{Discussão}

O discurso dos jovens da Geração Y torna explícita a passagem do regime Fordista/Taylorista para o Pós-Fordista, do regime industrial para o pós-industrial. A demanda e o desejo expressos em relação às organizações mostram a busca da superação da rigidez produtiva para uma organização flexível, ou o que se tem chamado de Toyotismo ou pós-industrialismo (HESPANHOL; NOGUEIRA; BÜLL, 2011).

Eles descreveram como a boa organização para trabalhar a organização que se caracteriza pela maior autonomia e o consequente controle do processo de trabalho pelo próprio trabalhador. Além disso, a boa organização para trabalhar é aquela que estimula a busca pelo desenvonto individual, o envolvimento afetivo do trabalhador e o enriquecimento constante da tarefa, a qual se traduz em novos desafios que enriquecerão as suas experiências profissionais. Todavia, os jovens relatam a onipresença da produtividade e da exigência de metas quase impossíveis, que acirra a contradição entre a possibilidade do desenvolvimento pessoal e os requisitos da produção. Isso pode provocar a impossibilidade de permanecer em uma organização. 
Nos resultados da pesquisa, é possível observar que a Geração Y se mostra como voluntária pronta para a integração e a assimilação a novas formas organizacionais pós-burocráticas (FAIRTLOUGH, 1996). A organização ideal é descrita com uma relação hierárquica reduzida e com caráter menos coercitivo e rígido, mais próxima de uma heterarquia (HEDLUND, 1986). A conexão e a experiência são mais importantes, com dispersão da liderança e equilíbrio de poder, com reciprocidade de comprometimento, pois os jovens da Geração Y aspiram a ser ouvidos em decisões importantes.

Os jovens relataram insatisfação com seus empregos atuais. Eles ressaltaram que o fator importante é o salário, o qual permite a sobrevivência. Os entrevistados identificaram a sua posição como de trabalhadores híbridos, pois algumas características do mundo pós-industrial já se prenunciam, principalmente os aspectos que exigem a permanente produção de si, enquanto outros elementos ainda pertencem ao universo taylorista-fordista. A convivência de ambos os aspectos cria o elemento híbrido apontado pelos jovens.

Eles reconhecem a necessidade de permanente criação/estudo/capacitação, que garanta o seu caráter polivalente, flexível, com conhecimento que enriqueça a sua carreira e a organização. Contudo, eles descrevem as organizações que não são boas para trabalhar como aquelas nas quais as tarefas são fragmentadas, com falta de comunicação, hierarquizadas e sem participação dos empregados. $\mathrm{O}$ momento descrito pelos jovens de ruptura com a organização e busca de novo emprego é exatamente o limite máximo do que eles entendem como o automatismo instrumental, repetitivo, previsível e sem reconhecimento salarial. A ação possível é a busca de autodesenvolvimento, da capacidade de começar novamente em outra empresa. Isso é resultado do discurso de que cada indivíduo é responsável pela sua própria carreira, o qual baliza as ações da Geração Y. Assim, os integrantes dessa geração demonstram comprometimento com a empresa, mas desde que percebam que essa relação está gerando resultados positivos (SANTOS, 2011). Enquanto os trabalhadores da Geração Y percebem que os valores da empresa estão alinhados com os seus valores, trabalham de forma comprometida. Todavia, quando percebem dissonâncias, não apresentam dificuldades para buscar novos caminhos (BROADBRIDGE; MAXWELL; OGDEN, 2007; HURST; GOOD, 2009).

A qualificação permanente é reconhecida como elemento chave para a empregabilidade e para recolocação profissional, junto com a rede de contatos. O conhecimento como meio de avanço profissional é reconhecido como uma aquisição, um patrimônio que é importante para que mantenham a carreira (DWYER, 2009). Abrem-se possibilidades emancipatórias que não podem ser desconsideradas. Se, por um lado, essa é uma exigência das organizações para o aumento de produtividade, por outro, essa é uma estratégia de valorização e relativa autonomia dos empregados, pois o conhecimento irá acompanhar os sujeitos. Daí a importância da flexibilidade de horários e da garantia de capacitação e formação permanentes. Esse é um elemento contraditório: possui uma resistência que, na sua contraface, é uma continuidade, que mantém 
o processo das organizações. O importante na sociedade pós-industrial é a corporalidade social, o conhecimento, a subjetividade, que agrega valor ao processo produtivo.

Viver e produzir tornou-se uma só coisa, o que os jovens reconhecem como a não separação trabalho e vida, que deveria existir. O processo de produção também não é apenas heteroproduzido, totalmente imposto, mas é um produto que continua, ele mesmo, a se produzir. É uma produção de vida social reconhecida pelos jovens e que eles podem disponibilizar para sua própria lógica. São recursos que servem aos trabalhadores para seu crescimento social e enriquecimento, mas que criam, para as empresas, a questão de como reter esses profissionais. De fato, a dificuldade em manter esses profissionais em uma única empresa é preocupante, já que essas pessoas saem de onde trabalham e levam o conhecimento adquirido consigo, o que obriga as organizações a realizarem um novo investimento em potenciais talentos (SANTOS, 2011).

A individualização é reconhecida como problemática para as organizações, pois impede a retenção das pessoas após o investimento nelas realizado. É o elemento que garante a singularidade e o diferencial de produtividade dos sujeitos. A mesma capacidade ativada pelas organizações se volta contra ela. $\mathrm{O}$ elemento de assujeitamento, presente no discurso dos jovens, também se manifesta como emancipação, o que não é diferente para outras gerações.

Outro dado ainda merece ser questionado. Diante do olhar e da escuta dos pesquisadores, o discurso dos jovens, organizado entre jargões de programas de gestão e teorias organizacionais, revelou o que os jovens pensam efetivamente ou foi uma performance discursiva, encenando o difícil equilíbrio de sua vida nas organizações? Não seria essa uma linha de tensão permanente, não só dos jovens, mas de todos os trabalhadores contemporâneos?

\section{Considerações finais}

Os resultados da pesquisa mostram que os jovens da Geração Y vivem uma situação híbrida nas organizações, pois aspiram uma organização pós-industrial e vivem em organizações com características ainda tayloristas-fordistas. Eles oscilam entre adaptação e a apropriação das competências, mantendo como valor o processo de auto-construção, que não pode ser diminuído a uma identidade pressuposta pela empresa e a uma reduzida capacidade de ação diante dessa perspectiva problemática.

A necessidade de estabilidade é entendida como um problema privado, em resposta à flexibilidade da empresa e estabelece um campo de tensionamento mais forte entre trabalho e vida e a capacidade de tolerar e conciliar as exigências do trabalho, as construções de sentido e interesse que constituem a base do agir. Essa é a base da sensibilidade aguda da Geração Y aos seus direitos e deveres que complementam a lógica do mérito e o trabalho visto não somente como obrigação moral ou econômica, mas como parte da vida que implica re- 
conhecimento afetivo e satisfação. A nova geração tornou-se um desafio pela alteração da ordem normativa. A nova ordem cognitiva tem uma ênfase nos fluxos e compartilhamentos, cujo foco desloca-se dos macroproblemas para uma ordem micropolítica. Esta envolve motivação, desejos, valores, significados com suas ambiguidades e tensões dos processos objetivadores e subjetivadores, ou seja, o modo como os percursos subjetivos da nova geração modificam as estruturas organizacionais, e esse ponto ainda não está resolvido, principalmente diante do novo paradigma da inovação.

Também é importante assinalar que a sociedade de controle altera parâmetros e limites segundo as quais estávamos habituados a ver e ser vistos. Ampliam-se e modificam-se as margens do visível, os modos de fazer ver, assim como os modos de ser visto. Uma reordenação dos regimes de visibilidade está em curso, o que implica uma reorientação da experiência dos espaços e do tempo e de sua relação com as tecnologias com as quais lidamos cotidianamente, como os jovens indicaram nas suas falas.

È possível observar que o controle sofreu uma ampla reordenação e tornou-se infinitesimal e produtivo, sem ser reconhecido como tal em algumas situações. Afinal, quem produz os perfis do LinkedIn, o sujeito ou os fluxos informacionais? Cabe lembrar que um regime de visibilidade, tal como o estamos vivendo na sociedade de controle, consiste não tanto no que é visto, mas no que produz para ser visto, no que torna possível o que se vê.

Características como a sobreposição de redes de controle, contínua e imediata comunicação e organização dos sistemas de controle de gestão como componente de um sistema geral de informação colocam as organizações como um elo da rede de acumulação biopolítica de informações que regulam a vida social. Uma das principais diferenças entre a sociedade disciplinar e a sociedade de controle é que a última está continuamente sujeita a várias linhas de visibilidade com diversas origens e capacidades. Não há mais a imobilidade disciplinar, o olhar é móvel e múltiplo com as tecnologias digitais. As tecnologias digitais não têm como objetivo transmitir uma espécie de determinismo tecnológico. As tecnologias digitais são conceituadas como "sociais" e não técnicas, não são máquinas de um componente, mas convergências múltiplas e flutuantes, permanentemente atualizadas para além das organizações, ou mesmo entre as diversas organizações que trabalham em colaboração.

Nesse sentido, cabe pensar como as novas tecnologias estabelecem definições contemporâneas para as tecnologias disciplinares. A exploração da integração dos sistemas de controle com outras redes de informação e monitoramento não convergem para normalizar um objeto que não é mais estático, mas móvel para o olhar do poder. Isso significa que a organização deve manter uma organização "para fora" e explorar sua interdependência recíproca com o novo ambiente do controle. Mas essa possibilidade ainda não é clara para os jovens entrevistados. O controle disciplinar "para dentro", com a combinação de estruturas horizontalizadas, é associada com rigorosos códigos de conduta 
e treinamentos comportamentais. A supervisão é realizada através das múltiplas linhas de visibilidade tecnológica.

No entanto, há uma enorme diferença entre a internalização do controle, que se transforma em auto-controle e a internalização da flexibilidade, que podemos observar na Geração Y. A necessidade de estabilidade laboral é entendida como um problema privado em resposta à flexibilidade da empresa, e estabelece um campo de tensionamento mais forte entre trabalho e vida e a capacidade de tolerar e conciliar as exigências do trabalho, as construções de sentido e interesse que constituem a base do agir. Tal perspectiva é o ponto de partida para estratégias de resistência e enfrentamento contra os mecanismos de controle e a colonização dos afetos postos pelo mundo organizacional.

A nova geração tornou-se um desafio pela alteração da ordem normativa indicada por Deleuze na sociedade de controle. A nova ordem cognitiva tem uma ênfase nos fluxos e compartilhamentos, cujo foco desloca-se dos macroproblemas para uma ordem micropolítica que envolve motivação, desejos, valores, significados com suas ambiguidades e tensões dos processos objetivadores e subjetivadores, isto é, no modo como os percursos subjetivos da nova geração modificam as estruturas organizacionais. Neste sentido, os dados analisados no presente estudo são relevantes e podem ser considerados pelos gestores de recursos humanos na elaboração e estruturação de futuras ações relacionadas à valorização e à retenção dos profissionais desta geração. Assim, a partir destas estratégias, as organizações estariam levando em consideração o modo de pensar destes colaboradores de forma mais eficaz.

Para finalizar, cabe ressaltar as limitações dessa pesquisa. Ela deve ser ampliada, com elementos quantitativos para que novos aspectos já revelados possam ser aprofundados e explorados, principalmente os relacionados com a Geração Y na sociedade brasileira.

\section{Referências Bibliográficas}

ALVES, Giovanni. Trabalho e subjetividade: o espírito do Toyotismo na era do capitalismo manipulatório. São Paulo: Boitempo, 2011.

ALLEN, Robin Lee. Managers Must Set Example for Gen Y Kidployees: Employee Recruitment and Molding. Nation's Restaurant News, Massachussetts, v. 39, n. 41, p. 54, 2005.

BALL, Kirstie et al. Democracy, surveillance and "knowing what's good for you": the private sector origins of profiling and the birth of "Customer Relationship Management". In: HAGGERTY, Kevin D.; SAMATAS, Minas (Eds). Surveillance and Democracy. New York: Routledge, 2010, p. 111-126.

BARDIN, Laurence. Análise de conteúdo. Lisboa: Edições 70, 2010.

HESPANHOL, Márcia Bernardo; NOGUEIRA, Francisco Ronald Capoulade; BÜLL, Sandra. Trabalho e saúde mental: repercussões das formas de precariedade objetiva e subjetiva. Arquivos Brasileiros de Psicologia, Rio de Janeiro, v. 63, p. 83-93, 2011. 
BHIMANI, Alnoor. Management accounting in the digital economy. Oxford: Oxford University Press, 2003.

BOLTANSKI, Luc; CHIAPELLO, Éve. O novo espirito do capitalismo. São Paulo: Martins Fontes, 2009.

BRASIL (Ministério da Saúde/Conselho Nacional de Saúde). Resolução no 466/12 de 12 de dezembro de 2012. Diário Oficial da União, Brasília, DF, 13 de junho de 2013 - Seção 1 - p. 59.

BROADBRIGE, Adelina M.; MAXWELL, Gillian A.; ODGEN, Susan M. Experiences, perceptions and expectations of retail employment for Generation Y. Career Development International, [S.1.], v. 12, n. 6, p. 523-544, 2007.

BUSK, Malene. Micropolitics: a political philosophy from Marx and beyond. In: PISTER Patricia (Ed). Micropolitcs of media culture: reading the rhizomes of Deleuze and Guattari. Amsterdam: Amsterdam University Press, 2001, p. 103-124

CASTELLS, Manuel. A sociedade em rede. 2a. ed. Rio de Janeiro: Paz e Terra, 1999.

DELEUZE, Gilles. Post-scriptum as sociedades de controle (1990). In: DELEUZE, Gilles. Conversações. Rio de Janeiro: Edições 34, 1992, p. 219-226

DWYER, Rocky. Prepare for the impact of the multi-generational workforce! Transforming Government: People, Process and Policy, [S.1.], v 3, n. 2, p. 101-110, 2009.

DYTCHWALD, Ken; ERICKSON, Tamara J.; MORISON, Robert. Workforce Crisis: How to Beat the Coming Shortage of Skills and Talent. Boston: Harvard Business School Press, 2006.

ELMORE, Tim. Generation iY: Our Last Chance to Save Their Future. Atlanta: Poet Garden, 2010 .

FAIRTLOUGH, Gerard. Innovation and Organization. In: DODGSON, Mark. (Ed.). The Handbook of industrial innovation. Cheltenham: Edward Elgar Pub., 1996.

FOUCAULT, Michel. Vigiar e Punir. Petropólis: Vozes, 1998.

. A sociedade disciplinar em crise. In: FOUCAULT, Michel. Ditos \& Escritos IV: estratégia poder-saber. Rio de Janeiro: Forense Universitária, 2003, p. 219-226.

Conversação sem complexos com um filósofo que analisa as "estruturas do poder". In: M. FOUCAULT. Ditos e escritos IV: estratégia, poder-saber. Rio de Janeiro: Forense Universitária, 2003, p. 307

FRANCIS-SMITH, Janice. Surviving and thriving in the multigenerational workplace. Journal Record, v. 1, n. 1, 2004.

HEDLUND, Gunnar. The Hypermodern MNC: a heterarchy? Human Resource Management, New York, v. 25, n. 1, p. 9-35, 1986.

HURST, Jessica; GOOD, Linda. Generation Y and career choice: the impact of retail career perceptions, expectations and entitlement perceptions. Career Development International, [S.1.], v. 14, n. 6, p. 570-593, 2009. 
PERRONE, C. M.; DIAS, A. C. G.; SANTOS, A.S.; SOBROSA, G.M.R.; ENGELMAN, S. Geração Y...

JOHNSON, Deborah; WAYLAND, Kent. Surveillance and transparency as sociotecnical systems of accountability. In: HAGGERTY, Kevin D.; SAMATAS, Minas (Eds). Surveillance and democracy. New York: Routledge, 2010, p.19-33

JOHNS, K. Managing Generational Diversity in the Workforce, [S.1.], 2004. Disponível em:

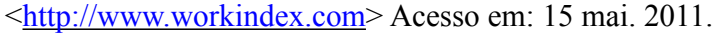

LÉVY, Pierre. Cibercultura. São Paulo: Edições 34, 1999.

. As Tecnologias da Inteligência: o futuro do pensamento na era da informática. São Paulo: Edições 34, 1993.

LIMA, Frederico O. A Sociedade Digital: o impacto da tecnologia na sociedade, na cultura, na educação e nas organizações. Rio de Janeiro: Qualitymark, 2000.

LOJKINE, Jean. A Revolução Informacional. São Paulo: Cortez, 1995.

MARTIN, Carolyn A.; TULGAN, Bruce. Managing Generation Y: Global Citizens Born in the Late Seventies and Early Eighties. US \& Canada: HRD Press Inc., 2001.

SANTOS, André Laizo. A Geração Y nas organizações complexas: um estudo exploratório sobre a gestão dos jovens nas empresas. 2011. 154f. (Mestrado em Administração) Programa de Pós-Graduação em Administração, Faculdade de Economia, Administração e Contabilidade, Universidade de São Paulo, São Paulo, 2011.

MINAYO, Maria Cecília de S. O desafio do conhecimento: pesquisa qualitativa em saúde. São Paulo: Hucitec, 2000.

RHEINGOLD, Howard. SmartMobs: The Next Social Revolution. Cambridge: Perseus, 2002.

SCHAFF, Adam. A sociedade informática. São Paulo: Brasiliense, 1995.

TAPSCOTT, Don. Growing Up Digital: The Rise of the Net Generation. New York: McGraw-Hill, 1999.

TURBAN, Efraim et al. Electronic Commerce: a Managerial Perspective. New Jersey: Prectice Hall, 2004.

Submissão em: 14/01/2013

Revisão em: 27/04/2014

Aceite em 30/04/2014

Cláudia Maria Perrone é Psicóloga, doutora em Psicologia pela Pontífica Universidade Católica do Rio Grande do Sul (PUC/RS), docente do departamento de Psicologia da Universidade Federal de Santa Maria (UFSM). Endereço para correspondência: Rua Marechal Floriano Peixoto, 1750, $3^{\circ}$ andar, sala 304. Centro. Santa Maria/RS. 90160-090. E-mail: cmperrone@ig.com.br 
Ana Cristina Garcia Dias é Psicóloga, doutora em Psicologia pela Universidade de São Paulo (USP), docente do departamento de Psicologia da Universidade Federal de Santa Maria (UFSM). E-mail: anacristinagarciadias@gmail.com

Anelise Schaurich dos Santos é Psicóloga, mestranda em Psicologia pelo Programa de Pós-graduação em Psicologia da Universidade Federal de Santa Maria (PPGP/

UFSM), bolsista CAPES/DS.

E-mail: anelise_ssantos@hotmail.com

Gênesis Marimar Rodrigues Sobrosa é Psicóloga, doutoranda em Psicologia Clínica pela Universidade do Vale do Rio dos Sinos (UNISINOS), docente da Escola de Psicologia da Faculdade Meridional (IMED). E-mail: genesispsi@yahoo.com.br

Selda Engelman é Administradora de empresas, doutora em Educação pela Universidade Federal do Rio Grande do Sul (UFRGS), docente do MBA em Gestão de Pessoas do Centro Universitário Metodista (IPA). E-mail: selda@terra.com.br 